\title{
Identification, diagnosis, and early intervention of children with developmental language disorder in Ningxia
}

\author{
Shi-Qi Chen ${ }^{1}$, Li-Juan Ge ${ }^{1}$, Guo-Qing Chen ${ }^{1}$, Wen-Juan He ${ }^{1}$, Juan-Juan Guo ${ }^{1}$, Yan Li $^{2}$, Lin Shi ${ }^{1}$, \\ Yan-Li Cheng ${ }^{1}$ \\ ${ }^{1}$ Department of Pediatrics, the General Hospital of Ningxia Medical University, Yinchuan, China; ${ }^{2}$ Department of Radiology, the General Hospital \\ of Ningxia Medical University, Yinchuan, China \\ Contributions: (I) Conception and design: SQ Chen, L Shi; (II) Administrative support: LJ Ge; (III) Provision of study materials or patients: SQ Chen, \\ LJ Ge, GQ Chen, WJ He, YL Cheng; (IV) Collection and assembly of data: SQ Chen, JJ Guo; (V) Data analysis and interpretation: SQ Chen, L Shi, \\ Y Li; (VI) Manuscript writing: All authors; (VII) Final approval of manuscript: All authors. \\ Correspondence to: Lin Shi. No. 804 South Shengli Street, Yinchuan 750004, China. Email: sworkq@163.com.
}

Background: It is reported that the incidence of language development disorder in children at the age of 2 is as high as $17.0 \%$. Timely discovery of the high-risk factors of language development disorder in children and early intervention can greatly reduce the incidence of language development disorder and shorten the course and condition of the patients with language development disorder. Therefore, in order to facilitate prompt diagnosis and early interventions for children with language development disorder (DLD) and improve their language ability, this study explored the influence of perinatal factors on the language development of children in Ningxia and identified the unfavorable and favorable factors that influenced language development.

Methods: Children diagnosed in the General Hospital of Ningxia Medical University during 2018-2021 who met the screening criteria for DLD and practical pediatric diagnostic criteria for DLD were enrolled in this study. Perinatal factors (gestational age, weight, sex, delivery mode, maternal age, presence of intrauterine infection, asphyxia) were retrospectively analyzed. The perinatal factors affecting language development were assessed using a one-way analysis of variance (ANOVA).

Results: Among 1,500 children aged 0-3, 240 cases (16.00\%) had language delay. Of these, 122 were male and 118 were female. There were 115 cases of comprehension and expression disorder, 30 cases of articulation disorder, and 90 cases of mixed manifestation. And there were 194 cases with definite intrauterine and perinatal high-risk factors or neonatal diseases, accounting for $80.83 \%$ of the total number of children with language delay.

Conclusions: In Ningxia, factors in the neonatal period are the main cause of DLD, followed by fetal and maternal factors. Ischemic encephalopathy is the most common factor.

Keywords: Developmental language disorder (DLD); diagnosis; early intervention

Submitted Nov 29, 2021. Accepted for publication Feb 18, 2022.

doi: $10.21037 / \mathrm{tp}-21-601$

View this article at: https://dx.doi.org/10.21037/tp-21-601

^ ORCID: 0000-0002-0248-3988. 


\section{Introduction}

Language is one of the most basic communication tools for human social and behavioral activities. The brain is the foundation of the language function, which not only stores a large amount of information (e.g., memory and intelligence) but also decodes and codes language. Language is a form of cognitive expression that reflects the thinking and psychological processes of the human brain (1). Developmental language disorder (DLD) in children refers to the inability of children in the language development period to understand and express language with language symbols due to various reasons compared to normal children in the expected period. Children's language development lags behind their actual age level, which is one of the most common language disorders in children. Language development delay hinders the development of children's social skills and affects their physical and mental development. If the language disorder or language development delay in infants and young children is not managed in a timely and effective manner, it seriously affects children's language understanding and expression ability and increases the incidence of attention deficit and learning difficulties at school age. This group will have a high-risk of developing various emotional and behavioral disorders, anxiety, depression, social withdrawal, communication disorders, irritability, hyperactivity, aggression, self-injury, and other psychological and behavioral problems. Studies outside of China have found that $30-40 \%$ of children who present to psychiatric departments for attention deficit and behavioral problems have language development problems (2-4).

DLD is the most common developmental disorder in children. Children with DLD have difficulties understanding or using oral language, written language, and other signaling systems. Children with DLD have a far lower level of language ability than normal children of the same age. A population-based prospective cohort study found that severe cognitive or social communication disorders at school age or adolescence usually originate from developmental disorders in early childhood (3). The incidence rate of children with developmental language impairment is about $15 \%$ in countries outside of China and 7\% in Shanghai. DLD has attracted significant attention from researchers around the world, and children's language development has become a hot topic in pediatric research (4).

Language is an important medium for information transmission and social communication. Research has shown that $50 \%$ of children with DLD have a language impairment that does not improve with age, which seriously affects their language expression ability and has a serious and lasting impact on their lives and their ability to learn later in life (5). Language barriers in children are associated with poor academic performance, limited employment in adulthood, and social communication barriers to a certain extent. School-age children have to accept special education or suspend their studies due to learning difficulties and behavioral problems, which has serious adverse effects on them and their caregivers (6). The period from $0-3$ years old is critical for a child's language development. Before 3 years old, children spend most of their time at home, and caregivers do not realize the adverse consequences of language disorders and the importance of early intervention and miss the most effective period for language intervention (7).

Therefore, to improve the early detection of highrisk children with DLD, and achieve early diagnosis and treatment, this study explored the influence of perinatal factors on the language development of infants in Ningxia by examining the favorable and unfavorable factors affecting the language development of children. It is of great clinical and social significance to reduce the incidence of DLD and improve the quality of life of children. We present the following article in accordance with the STROBE reporting checklist (available at https://tp.amegroups.com/article/ view/10.21037/tp-21-601/rc).

\section{Methods}

\section{Participants}

Children aged 0-3 diagnosed in the General Hospital of Ningxia Medical University from 2018 to 2021 and their fathers and mothers were examined and evaluated by a questionnaire. A total of 1,500 children were included in the study; 740 were male and 750 were female. A total of 1,500 questionnaires were collected. All procedures performed in this study involving human participants were in accordance with the Declaration of Helsinki (as revised in 2013). The study was approved by institutional committee of the General Hospital of Ningxia Medical University (No. KYLL-2021-691). Individual consent for this retrospective analysis was waived.

\section{Study design}

\section{Questionnaire design}

The questionnaire for child language development is shown 
Table 1 Questionnaire on child language development

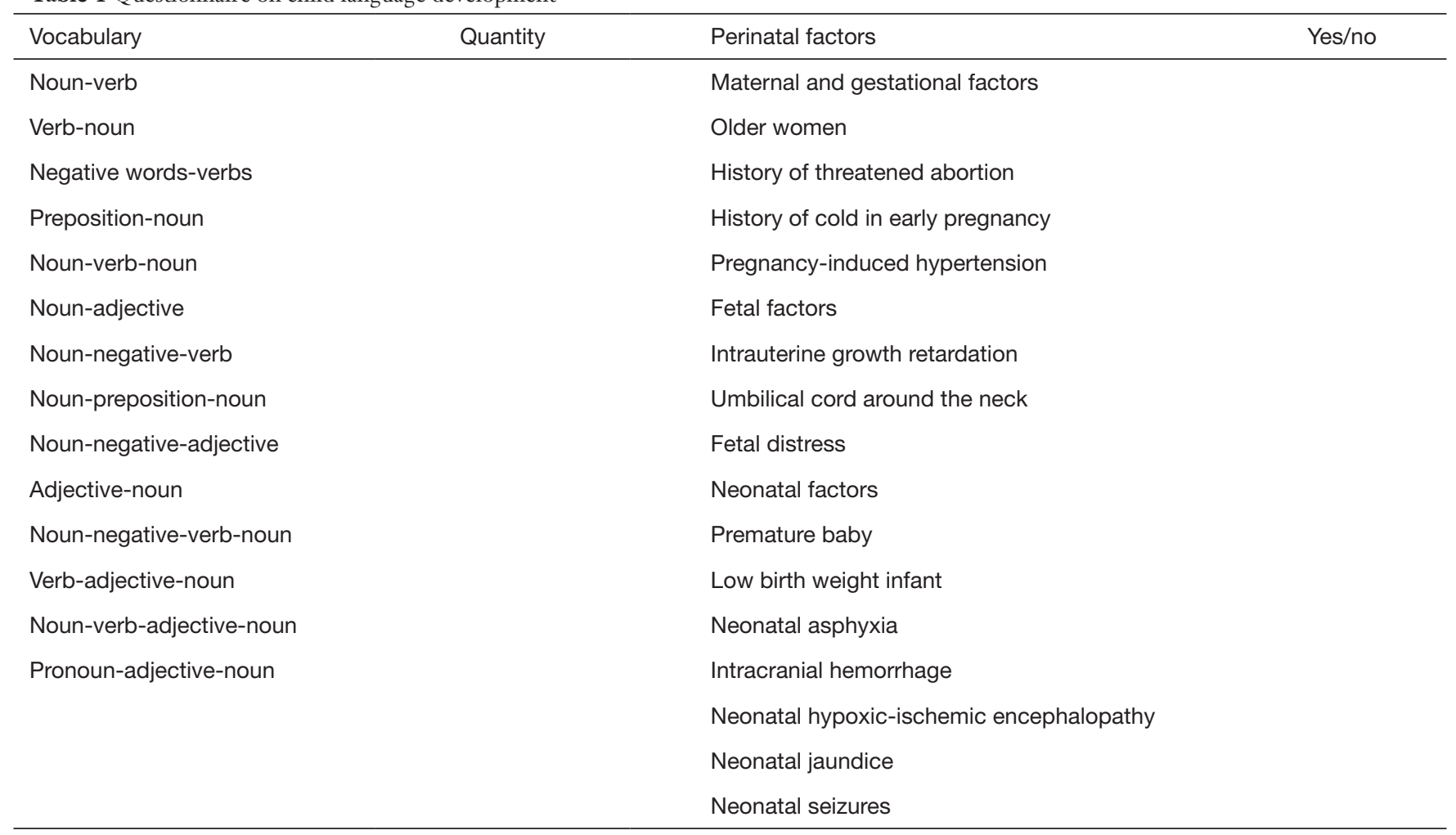

in Table 1. Parents were required to fill in the vocabulary, auxiliary words, and expression structures that their children could express spontaneously. The inclusion criteria were as follows: children without hearing abnormalities as shown through related audiology examinations (8); children who showed a vocabulary of less than 30 words in 24 months; and children who showed fewer than 3 (boys) and 5 (girls) structural expressions in 30 months. The criteria for suspected DLD were as follows: vocabulary less than 50 words at 24 months, structural expressions of less than 5 for boys and 8 for girls at 30 months, Zhufutang Practical Pediatrics. This book of Zhufutang Practical Pediatrics is a pediatrics work which combines medicine, teaching, research and prevention closely, and is of great benefit to improving pediatricians (9), and a vocabulary containing fewer words than children of the corresponding age. A total of 240 patients were found to have DLD. The family questionnaire focused on the perinatal conditions of each child.

\section{Children with language delay of perinatal factors}

The perinatal factors, including gestational age, weight, sex, delivery mode, maternal age, intrauterine infection, intrauterine asphyxia, postpartum asphyxia, premature delivery, hypoxic-ischemic encephalopathy, neonatal jaundice, and neonatal convulsion, were investigated and retrospectively analyzed.

\section{Quality control}

Based on strict quality control, parents' questionnaires were used for research, and parents were assisted to complete the questionnaire. The recovery rate of these questionnaires was $100 \%$.

\section{Statistical analysis}

Using one-way analysis of variance, factors affecting the language development of 3 -year-old children in the perinatal period were analyzed.

\section{Results}

Analysis of language delay and perinatal abnormalities in children

Among the 1,500 children aged 0-3, 240 cases (16.00\%) had 
Table 2 Language delay and perinatal abnormalities in children

\begin{tabular}{|c|c|c|}
\hline Perinatal factors & $\mathrm{n}$ & Composition ratio (\%) \\
\hline Older women & 26 & 13.40 \\
\hline History of threatened abortion & 27 & 13.92 \\
\hline History of cold in early pregnancy & 53 & 27.32 \\
\hline \multicolumn{3}{|l|}{ Fetal factors } \\
\hline Intrauterine growth retardation & 14 & 7.22 \\
\hline Umbilical cord around the neck & 8 & 4.37 \\
\hline Fetal distress & 36 & 19.70 \\
\hline Neonatal asphyxia & 63 & 32.47 \\
\hline Intracranial hemorrhage & 7 & 3.61 \\
\hline Neonatal hypoxic-ischemic encephalopathy & 47 & 21.53 \\
\hline Neonatal jaundice & 36 & 24.23 \\
\hline Neonatal seizures & 28 & 14.43 \\
\hline
\end{tabular}

a language delay. There were 122 males and 118 females. There were 115 cases of comprehension and expression disorder, 30 cases of articulation disorder, and 90 cases of mixed manifestation. The questionnaire of factors in the perinatal period included gestational age, weight, gender, mother's age, mode of delivery, the presence of intrauterine infection and intrauterine asphyxia, postpartum asphyxia, presence of hypoxic ischemic encephalopathy, intracranial hemorrhage, abnormal fetal development, preterm birth, neonatal jaundice, and neonatal convulsions. Multiple factors could occur simultaneously. There were 194 cases with definite intrauterine and perinatal high-risk factors or neonatal diseases, accounting for $80.83 \%$ of the total number of children with a language delay. There were 26 cases of older pregnant women, 27 cases of threatened abortion, 53 cases of cold in early pregnancy, and 14 cases of pregnancy-induced hypertension. Children born with their umbilical cord around their neck occurred in 8 cases, fetal distress occurred in 36 cases, and fetal growth retardation occurred in 14 cases. There were 44 premature infants, 13 infants with low birth weights, 63 cases of neonatal asphyxia, 7 cases of intracranial hemorrhage, 42 cases of neonatal hypoxic encephalopathy, 36 cases of neonatal jaundice, and 28 cases of neonatal convulsions. The specific composition is shown in Table 2.

\section{Perinatal conditions and classification of language disorders}

Of the 240 children with a language delay, there were 115 cases of comprehension and expression disorder, 30 cases of an articulation disorder, and 90 cases of mixed manifestation. The results were compared with perinatal conditions (Table 3).

\section{Analysis of single factors affecting children's language development in the perinatal period}

The analysis of variance method was used to conduct a single factor analysis of perinatal factors that may affect children's language ability. The results are shown in Table 4.

\section{Discussion}

Language development delay refers to a delay in a child's oral expression ability or language understanding ability compared to the normal developmental level of children 
Table 3 Perinatal conditions and classification of language disorders

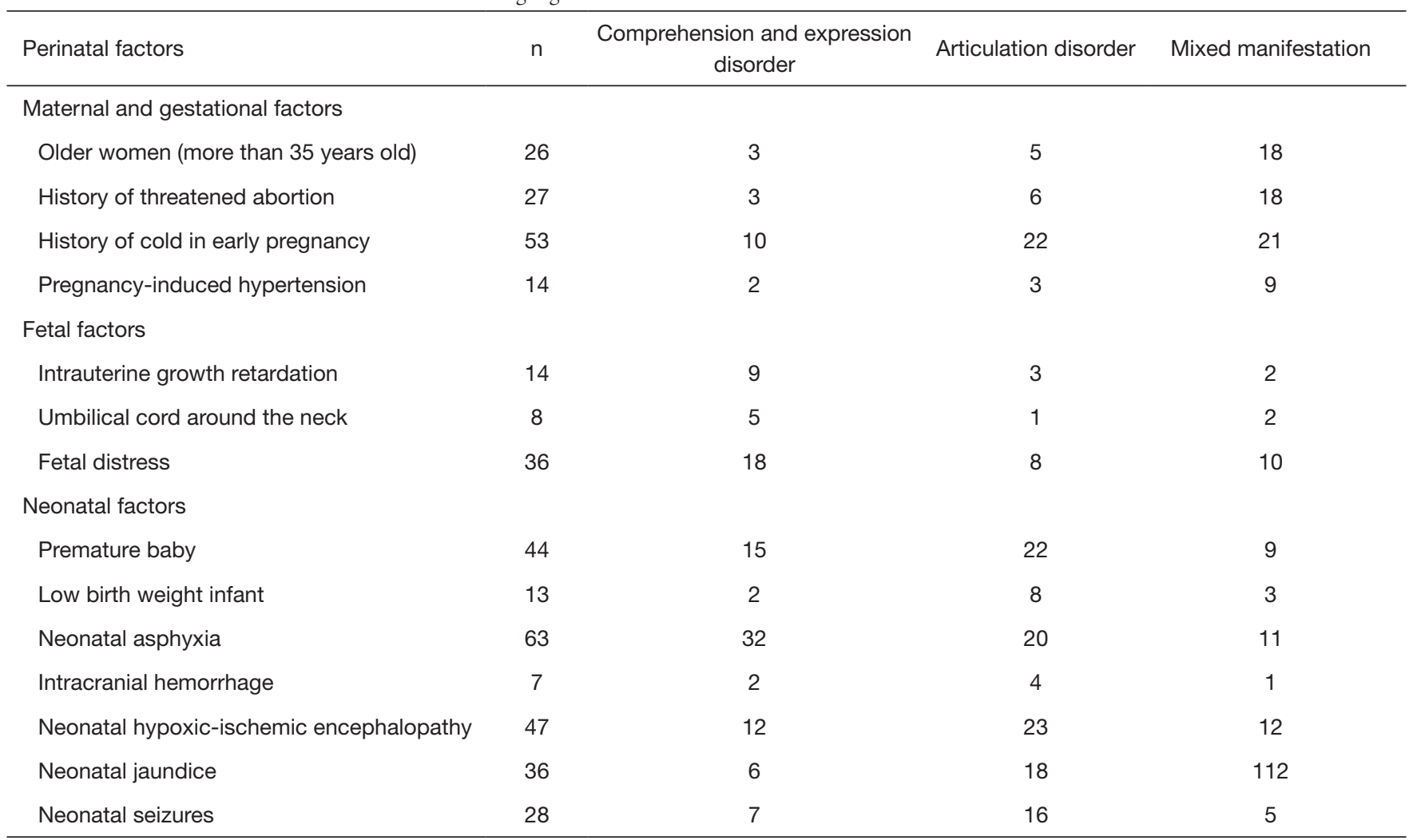

of the same age. Mental deficiency, hearing impairment, articulatory organ diseases, central nervous system diseases, a poor language environment, and other factors are common causes of developmental delay (10). The phenomenon of language development delay is called idiopathic language development disorder or DLD. The etiology of DLD is not clear at present but may be related to certain abnormal sensory functions of the brain. Generally, it is mainly caused by congenital factors.

Speech is one of the most important expressions of language; it is a process through which individuals communicate and express thoughts, opinions, and emotions (11). Children's language development is influenced by many factors. It can impact all aspects of a child's language function (such as listening, speaking, reading, writing) to varying degrees and lead to secondary disorders (such as psychological, intellectual, and social adjustment, among others). Therefore, the clinical research and treatment of language delay in children are imperative. However, in clinical practice, language development disorders often do not receive enough attention. For example, clinical treatment of patients with dysplasia often ignores the problem of abnormal language development. People with simple language development disorders, such as delayed speech, are also overlooked and not given the necessary attention. This can result in missing the best treatment period for delayed language development of children.

Language ability is an important part of a child's intelligence. Language comprehension skills develop in children before the age of 2. Children learn language expression after the age of 2. Language development is perfected by the age of 4 . Therefore, the $0-3$-year-old period is critical for the development of intelligence because it is a critical period for the development of children's language. During this period, intervening in a timely manner can promote children's language development. Early intervention can mitigate the impact of high-risk factors and sociocultural factors which lead to mental retardation and improve the overall level of the intellectual development of children (12).

Specific disorders which impact language learning include developmental aphasia and acquired aphasia. Developmental aphasia is the delay of one or all aspects of language function or ability, which prevents a child from understanding and expressing his or her language to the same level as other children of the same age. Acquired aphasia refers to the impairment of language understanding 
Table 4 Single-factor analysis of children's language ability and perinatal factors

\begin{tabular}{|c|c|c|c|c|c|}
\hline Perinatal factors & $\mathrm{n}$ & Mean & SD & $\mathrm{F}$ & $\mathrm{P}$ \\
\hline Older women (more than 35 years old) & 26 & 110.75 & 12.71 & & \\
\hline History of threatened abortion & 27 & 109.87 & 13.88 & & \\
\hline History of cold in early pregnancy & 53 & 112.06 & 13.74 & & \\
\hline Fetal factors & & & & 12.36 & $<0.01$ \\
\hline Intrauterine growth retardation & 14 & 96.58 & 10.12 & & \\
\hline Umbilical cord around the neck & 8 & 97.86 & 11.07 & & \\
\hline Fetal distress & 36 & 106.24 & 10.52 & & \\
\hline Neonatal asphyxia & 63 & 104.56 & 12.06 & & \\
\hline Intracranial hemorrhage & 7 & 99.74 & 10.95 & & \\
\hline Neonatal hypoxic-ischemic encephalopathy & 47 & 102.35 & 11.26 & & \\
\hline Neonatal jaundice & 36 & 101.99 & 10.87 & & \\
\hline Neonatal seizures & 28 & 101.17 & 10.44 & & \\
\hline
\end{tabular}

and expression caused by central nervous system injury, dysplasia, or dysfunction (13). These two specific aphasia disorders are not readily diagnosed clinically and are therefore included in language delay.

Language development disorder can be caused by the negative influence of the language environment. In these cases, the child does not have congenital issues but is deprived or separated from the language environment in the early stage of language learning.

Abnormalities of articulation organs can also impact on a child's language development. This refers to motor diseases, such as cerebral palsy, and organic diseases, such as cleft palate. These diseases hinder the expression of language and cause language development delay (13). There were 6 cases of cerebral palsy and 2 cases of cleft palate in this study.

Conditions before and after birth, such as intrauterine and perinatal risk factors, also significantly impact a child's language development. Threatened abortion in early pregnancy, a history of the mother catching a cold in early pregnancy, hypertension, diabetes, and anemia in late pregnancy can cause brain damage or affect the development of the fetus and are influential for delayed language development (14). A Caesarean section delivery lacks stimulation of the fetus compared to a vaginal delivery, which can also affect the psychomotor development of children and manifest as a language delay. Liu et al.'s study (15) found that cesarean section correlated with language development delay $(\mathrm{r}=0.712 ; \mathrm{P}<0.05)$. The results in our study were consistent with this. Furthermore, the overall delayed development of premature and low birth weight infants ultimately affects their acceptance in the outside world and impacts their language development. Ettenberger et al. (16) showed that infants with very low birth weights were at a high risk of language development disorder and may even experience literacy defects and learning difficulties after school age. There were 64 cases of premature infants and 19 cases of infants with low birth weights in this study, which accounted for a large proportion of all infants with DLD.

Previous studies in China and around the world have found that abnormal brain development caused by genes can also cause language delay. Seol et al. (17) found that genetic gene affects early brain development. They explored the influence of congenital factors and environmental factors on language development by comparing the vocabulary of twin children and showed that the influence of genetic gene on language development at the age of 2 was significantly greater than that of environmental factors.

Language is also closely related to intellectual development. 
The psychology community believes that language ability is a reflection of intelligence, and the degree of language impairment is positively correlated with intelligence is mild, moderate and severe (18). Therefore, intelligence assessment is important in the diagnosis of language disorders. However, the language part of many intelligence scales cannot measure the language ability of children with acute language disorders, such as aphasia and stuttering. The cognitive level of these children can be determined by using the intelligence test and identifying language barriers and mental retardation. Children's language perception ability can be determined through picture vocabulary tests, and developmental language delays can be identified using the Denver Developmental Screening Test. Future training and therapy could be targeted at this.

According to this study, 240 of the 1,500 children in Ningxia had a language delay, accounting for $16.00 \%$, including 122 males and 118 females. Therefore, there was a high incidence of language delay in children and more attention should be paid to this issue. There was no gender difference in language delay. Neonatal factors were the main cause of language delay, followed by maternal factors during pregnancy and fetal factors. Among the neonatal factors, there were 47 cases of neonatal hypoxic-ischemic encephalopathy, accounting for $21.53 \%$ of the total cases of language delay. In terms of the classification of language disorders, maternal and gestational factors were mainly associated with mixed manifestation, fetal factors were mainly associated with comprehension and expression disorders, and neonatal factors were mainly related to articulation disorders.

Studies in China and globally have shown that the effect of early intervention between $0-3$ years old is better than the effect after a child is 3 years old. The improvement of language ability after intervention can effectively reduce children's problem behavior, which means that early intervention has a high return on investment $(19,20)$. Therefore, we should pay attention to the early recognition and intervention of language and speech disorders in children. We should increase basic research into early recognition and intervention, such as developing assessment tools for early recognition and formulating national norms. Long-term follow-up studies should also be conducted to develop optimal intervention paradigms. We should establish a system of early identification, referral, diagnosis, and intervention, advance the age of screening, and improve the language function of children with disabilities through intervention as early as possible, reduce their problem behaviors, and prevent possible reading problems. In addition, more professionals should be trained in diagnosis and intervention of language delays.

In conclusion, this study found that factors in the perinatal period can significantly affect language development in children. There were 240 cases of children with a language delay. Of these, there were 194 cases with definite intrauterine and perinatal high-risk factors or neonatal diseases, accounting for $80.83 \%$ of the total number of children with a language delay. Efforts to prevent language delays in children should be focused on perinatal factors, which are important for a child's language development. In Ningxia, factors in the neonatal period were found to be the main cause of DLD, followed by fetal and maternal factors. Ischemic encephalopathy was the most common factor. By identifying the perinatal risk factors affecting children's language development, this study provides a direction for early detection, early diagnosis, and early treatment of children at high risk of language development delay. Reducing the incidence of language development disorder and improving the quality of life of children is of great clinical and social significance.

\section{Acknowledgments}

Funding: None.

\section{Footnote}

Reporting Checklist: The authors have completed the STROBE reporting checklist. Available at https:// tp.amegroups.com/article/view/10.21037/tp-21-601/rc

Data Sharing Statement: Available at https://tp.amegroups. com/article/view/10.21037/tp-21-601/dss

Conflicts of Interest: All authors have completed the ICMJE uniform disclosure form (available at https://tp.amegroups. com/article/view/10.21037/tp-21-601/coif). The authors have no conflicts of interest to declare.

Ethical Statement: The authors are accountable for all aspects of the work in ensuring that questions related to the accuracy or integrity of any part of the work are appropriately investigated and resolved. All procedures performed in this study involving human participants were in accordance with the Declaration of Helsinki (as revised in 2013). The study was approved by institutional committee of the General Hospital of Ningxia Medical University (No. 
KYLL-2021-691). Individual consent for this retrospective analysis was waived.

Open Access Statement: This is an Open Access article distributed in accordance with the Creative Commons Attribution-NonCommercial-NoDerivs 4.0 International License (CC BY-NC-ND 4.0), which permits the noncommercial replication and distribution of the article with the strict proviso that no changes or edits are made and the original work is properly cited (including links to both the formal publication through the relevant DOI and the license). See: https://creativecommons.org/licenses/by-nc-nd/4.0/.

\section{References}

1. van Agt HM, van der Stege HA, de Ridder-Sluiter H, et al. A cluster-randomized trial of screening for language delay in toddlers: effects on school performance and language development at age 8. Pediatrics 2007;120:1317-25.

2. Roberts MY, Kaiser AP. Early intervention for toddlers with language delays: a randomized controlled trial. Pediatrics 2015;135:686-93.

3. Sokhadze EM, Casanova MF, Tasman A, et al. Electrophysiological and Behavioral Outcomes of Berard Auditory Integration Training (AIT) in Children with Autism Spectrum Disorder. Appl Psychophysiol Biofeedback 2016;41:405-20.

4. Mossabeb R, Wade KC, Finnegan K, et al. Language development survey provides a useful screening tool for language delay in preterm infants. Clin Pediatr (Phila) 2012;51:638-44.

5. Siu AL. US Preventive Services Task Force. Screening for Speech and Language Delay and Disorders in Children Aged 5 Years or Younger: US Preventive Services Task Force Recommendation Statement. Pediatrics 2015;136:e474-81.

6. Chen YF. Chinese classification of mental disorders (CCMD-3): towards integration in international classification. Psychopathology 2002;35:171-5.

7. Mainela-Arnold E, Alibali MW, Hostetter AB, et al. Gesturespeech integration in children with specific language impairment. Int J Lang Commun Disord 2014;49:761-70.

8. Kiebzak W, Kowalski IM, Domagalska M, et al. Assessment of visual perception in adolescents with a history of central coordination disorder in early life - 15year follow-up study. Arch Med Sci 2012;8:879-85.

9. Morrow CE, Bandstra ES, Anthony JC, et al. Influence of prenatal cocaine exposure on early language development: longitudinal findings from four months to three years of age. J Dev Behav Pediatr 2003;24:39-50.
10. Im SH, Park ES, Kim DY, et al. The neuroradiological findings of children with developmental language disorder. Yonsei Med J 2007;48:405-11.

11. Jansson-Verkasalo E, Valkama M, Vainionpää L, et al. Language development in very low birth weight preterm children: a follow-up study. Folia Phoniatr Logop 2004;56:108-19.

12. Dale PS, Simonoff E, Bishop DV, et al. Genetic influence on language delay in two-year-old children. Nat Neurosci 1998;1:324-8.

13. Wallace IF, Berkman ND, Watson LR, et al. Screening for Speech and Language Delay in Children 5 Years Old and Younger: A Systematic Review. Pediatrics 2015;136:e448-62.

14. Oetting JB, Pruitt SL, Roy VP. Community-Based Caregiver Training: A Rationale and Model for Early Interventionists Who Work with Low-Income Families. Zero to Three 2006;27:13-21.

15. Liu SL, Jiang SM, Zhang L. The Factors Causing Language Development Delay in Children. Journal of Audiology and Speech Pathology 2006;14:179-81.

16. Ettenberger $M, C$ Rojas Cárdenas, Parker $M$, et al. Family-centred music therapy with preterm infants and their parents in the Neonatal Intensive Care Unit (NICU) in Colombia-A mixed-methods study. Nordic Journal of Music Therapy 2017;26:207-34.

17. Seol KI, Song SH, Kim KL, et al. A comparison of receptive-expressive language profiles between toddlers with autism spectrum disorder and developmental language delay. Yonsei Med J 2014;55:1721-8.

18. Allen J, Marshall CR. Parent-Child Interaction Therapy (PCIT) in school-aged children with specific language impairment. Int J Lang Commun Disord 2011;46:397-410.

19. Hebbeler K, Spiker D, Bailey D, et al. Early Intervention for Infants and Toddlers with Disabilities and their Families: Participants, Services, and Outcomes. Final Report of the National Early Intervention Longitudinal Study, 2007.

20. Bassewitz J. About Bright Futures: Guidelines for Health Supervision of Infants, Children, and Adolescents. N C Med J 2015;74:28-33.

(English Language Editors: C. Betlazar-Maseh and C. Mullens)

Cite this article as: Chen SQ, Ge LJ, Chen GQ, He WJ, Guo JJ, Li Y, Shi L, Cheng YL. Identification, diagnosis, and early intervention of children with developmental language disorder in Ningxia. Transl Pediatr 2022;11(2):204-211. doi: 10.21037/ tp-21-601 